\title{
Comparison of Legionella Biofilm Formations at Three Different Temperatures in Liquid Flow, in Static Liquid and on Agar Plate*
}

\author{
Tadashi KONISHI**, Akira NISHIZONO***, Tetsu YAMASHIRO**** \\ and Michio $\mathrm{KOIDE} * * * * *$ \\ ** Department of Mechanical Engineering, Oita National College of Technology \\ 1666 Maki, Oita, Japan \\ E-mail: konishi@oita-ct.ac.jp \\ *** Faculty of Medicine, Oita University \\ 1 Idai-gaoka, Yufu, Japan \\ **** Institute of Tropical Medicine, Nagasaki University \\ 1-12-4 Sakamoto, Nagasaki, Japan \\ ***** Faculty of Medicine, University of the Ryukyus \\ 1 Senbaru, Nishihara, Okinawa, Japan
}

\begin{abstract}
The biofilm formation of Legionella pneumophila on glass was examined under nutrient water flow condition at $37^{\circ} \mathrm{C}, 40^{\circ} \mathrm{C}$, and $42^{\circ} \mathrm{C}$. The three-dimensional structures of 8-days biofilm were analyzed using confocal laser scanning microscopy. It was revealed that the properties of the biofilms were influenced significantly by temperature changes. Equivalent outer diameters of the microcolonies were $39 \mu \mathrm{m}$ at $37^{\circ} \mathrm{C}, 189 \mu \mathrm{m}$ at $40^{\circ} \mathrm{C}$ and $359 \mu \mathrm{m}$ at $42^{\circ} \mathrm{C}$, respectively. The most interesting observation was that the microcolonies show areas of hollowing. The hollowness or emptiness is $37 \%$ at $37^{\circ} \mathrm{C}, 52 \%$ at $40^{\circ} \mathrm{C}$ and $74 \%$ at $42^{\circ} \mathrm{C}$, respectively. The average number of bacteria per single colony was c.a. $1 \times 10^{5}$ at $37^{\circ} \mathrm{C}$. Also, bacteria lengths were compared among the biofilms in liquid flow, those in static liquid and those on BCYE- $\alpha$ agar plate. In the liquid flow, the average bacteria length was $4.4 \mu \mathrm{m}$ at $37^{\circ} \mathrm{C}, 2.9 \mu \mathrm{m}$ at $40^{\circ} \mathrm{C}$ and $3.5 \mu \mathrm{m}$ at $42^{\circ} \mathrm{C}$, respectively, while in the static liquid and on agar plate the lengths increased with the rise of temperature. Our experiments results on the biofilm formation of $L$. pneumophila will provide the basis for a better understanding of the sessile mode of life of L. pneumophila.
\end{abstract}

Key words: Legionella, Biofilm, Flow Channel, Temperature Effect, Microcolony

\section{Introduction}

Bacteria of the genus Legionella is widely found in the natural environment, and causes Pontiac fever and Legionella pneumonia. Legionella are Gram-negative, aerobic, and rod-shaped with one or more polar flagella as shown in Fig.1 ${ }^{(1)}{ }^{(2)}$. The number of Legionella spp. associated with pneumonia was rarely reported in Japan until April 1999, when a new "Law Concerning the Prevention of Infectious Diseases and Patients with Infectious Diseases (New Law on Infectious Diseases)" was enacted. The number of 


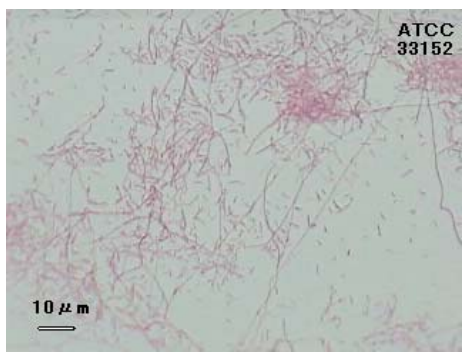

Fig.1 Photograph of type strain of L. pneumophila serogroup 133152

reported Legionella pneumonia cases has since increased dramatically: 56 cases in 1999, 281 cases in 2005, and 892 cases in $2008^{(3)}$. In 2002, an outbreak of Legionellosis occurred at a public bathhouse in Miyazaki, Japan. In the outbreak, 32 cases were laboratory confirmed as Legionella pneumonia and 263 cases were suspected to be so. Meanwhile, Korea Centers for Disease Control and Prevention received the reports of 6 cases in 1995 , 24 cases in $2009^{(4)}$. Although legionellosis in Korea is less than one-tenth of that in Japan, it is steadily increasing. Legionella spp. is a ubiquitous intracellular microorganism present in natural and man made aquatic environments ${ }^{(5)-(7)}$. Figure 2 shows Legionella infection path to human lung. The bacteria proliferate in stagnant warm water, as found in cooling towers $^{(8)}$, evaporative condensers of large air-conditioning systems, plumbing systems, showers, whirlpool spas, dental clinic settings, and similar disseminators ${ }^{(9)}$. Legionnaires' disease is infected by inhaling small droplets of water suspended in the air, which contain the Legionella bacteria ${ }^{(10)}$. Legionellae hardly grow at temperatures below $20^{\circ} \mathrm{C}$ or above $50^{\circ} \mathrm{C}$ and are easily killed at temperatures above $60^{\circ} \mathrm{C}$. Elevated water temperature is one of the methods used to eradicate Legionella from water systems. In hospital or public water systems, Legionellae can be killed by raising the temperature of the hot water supply to 70 to $80^{\circ} \mathrm{C}^{(11)(12)}$. Japanese guidelines for prevention of legionella infection recommend that the temperature of water stored in hot and warm water systems must be maintained at a minimum of $60^{\circ} \mathrm{C}$.

It is reported that Legionella spp. can survive inside biofilms under high temperature of approximately $70^{\circ} \mathrm{C}$ and high chlorination of $50 \mathrm{mg} \mathrm{L}^{-1}{ }^{(13)}$. Biofilms are composed of mineral particles, a variety of microorganisms, and a network of slime, or glycocalyx, that binds the microorganisms and particles together ${ }^{(14)(15)}$. Biofilms exist wherever surfaces contact water. The surface colonization can take place either on the solid-liquid interface or on the air-liquid interface. High concentrations of Legionellae are generally associated with the proliferation of host protozoa in biofilms. Free-living protozoa, e.g amoeba, may enhance the multiplication of bacteria, serve as a transmission vector, or serve as a shelter against unfavorable environmental conditions, such as the presence of disinfectants ${ }^{(16)(17)}$. In our previous research, we developed the bacterial biofilm reactor with an accurate temperature gradient control ${ }^{(18)}$. The simulator is able to reach a set temperature within 2 hours and maintain temperature as accurate as $\pm 0.1^{\circ} \mathrm{C}$ of the set temperature. Ten

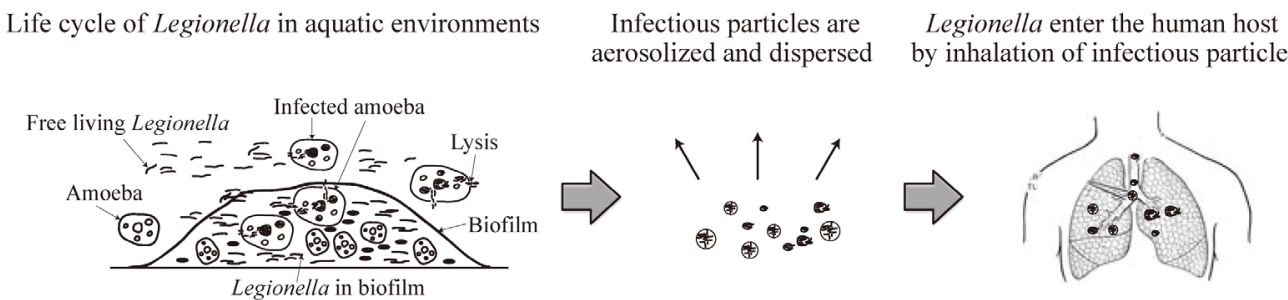

Fig.2 Legionella infection path to human lung 
aluminum blocks with cylindrical chambers holding a glass test tube for incubating Legionellae are placed side by side in a row to give 10 different culture temperatures. The influence of temperature on the morphological changes of Legionella pneumophila biofilm was investigated in broth and on agar at temperatures between 30.0 to $47.0^{\circ} \mathrm{C}$ under the static condition. It was revealed that temperature was a key factor which affects the biofilm formation on glass surface under the static cultures. However, in public watering systems, it is important to consider liquid flow within the system, for liquid flow influences the processes of bacterial attachment and detachment and development within the biofilm. The velocity of liquid flow which directly affects the surface plays an important part in the growth of biofilms.

In order to design and operate watering systems that deliver the bacteria-free quality water, we should understand how biofilms develop under liquid flow conditions, what problems they can cause, and how they can be controlled. This study demonstrates the development of a monospecies model biofilm for L. pneumophila, bacteria which are known to form biofilms in the natural environment, though this model does not reflect the complexity of the sessile lifestyle of $L$. pneumophila found in the natural environment We describe the development of the flow type biofilm simulator in order to analyze biofilm formation under liquid flow conditions. Bacterial biofilm formations are influenced more by temperature changes than flow conditions. We would like to reveal some differences of bacterial biofilm formations in liquid flow, those in static liquid and those on agar plate.

\section{Materials and Methods}

\section{Bacterial strain, inoculation}

The strains of L. pneumophila serogroup 1 were employed for this experiment. A type strain of L. pneumophila serogroup 133152 was obtained from the American Type of Culture Collection (ATCC). The strain had been previously frozen at $-86^{\circ} \mathrm{C}$ in vials containing $10 \%$ skim milk. The vials were thawed at room temperature, and the contents were streaked onto buffered charcoal-yeast extract agar supplemented with $0.1 \% \alpha$ -ketoglutarate (BCYE- $\alpha$ ). The agar plates were incubated for $72 \mathrm{~h}$ at $37^{\circ} \mathrm{C}$. Growth was harvested from plates with a platinum loop and placed into fresh BCYE- $\alpha$ medium containing supplements of $1 \%$ L-cysteine and $1 \%$ ferric pyrophosphate and incubated shaking in flask overnight at $37^{\circ} \mathrm{C}$. Transfer the culture into $50 \mathrm{ml}$ centrifuge tube and centrifuge at $1500 \mathrm{rpm}$ for $10 \mathrm{~min}$ at RT. Supernatant was removed and the pellet cells were resuspended in $10 \mathrm{ml}$ sterile distilled water. The culture was then diluted with sterile distilled water to measure an optical density at $660 \mathrm{~nm}$ (OD660).

\section{Liquid flow chamber system}

In order to monitor the biofilm formation of L. pneumophila under dynamic flow conditions, a liquid flow chamber system was set up as shown in Fig.3(A). The 4 removable clear glass slides (26mm wide and $76 \mathrm{~mm}$ long) were mounted in the flow channel to give $L$. pneumophila the opportunity to develop biofilms on the slides as shown in Fig.3(B). The test section of biofilm sampling device (the flow channel) has a length of $304 \mathrm{~mm}$ and a rectangular cross section of $26 \mathrm{~mm}$ wide and $10 \mathrm{~mm}$ height. The culture medium was circulated through silicon tubes (I/D $4.8 \mathrm{~mm}$ ) between two bottles (Nalge Nunc International K.K., 2126-2000) by means of a peristaltic pump (Masterflex Inc., 7524-40, 77201-60). Two glass flow breaks (BioSurface Technologies Corp., FC50) were used on both the inlet and the outlet sides of the biofilm sampling device to insure a steady feed rate. A cylinder bubble trap (BioSurface Technologies Corp., FC33) with air release cock captures air bubbles released from the flowing culture medium. Since Legionella require oxygen for their survival, to ensure the aerobic conditions during the experiment, air was pumped into the system through the air inlet line. Small air pumps were used to pump air through silicon tube to a $0.2 \mu \mathrm{m}$ polycarbonate membrane filter (Nippon Genetics Co. Ltd., GM4210) 
(A)

0.2 um filter

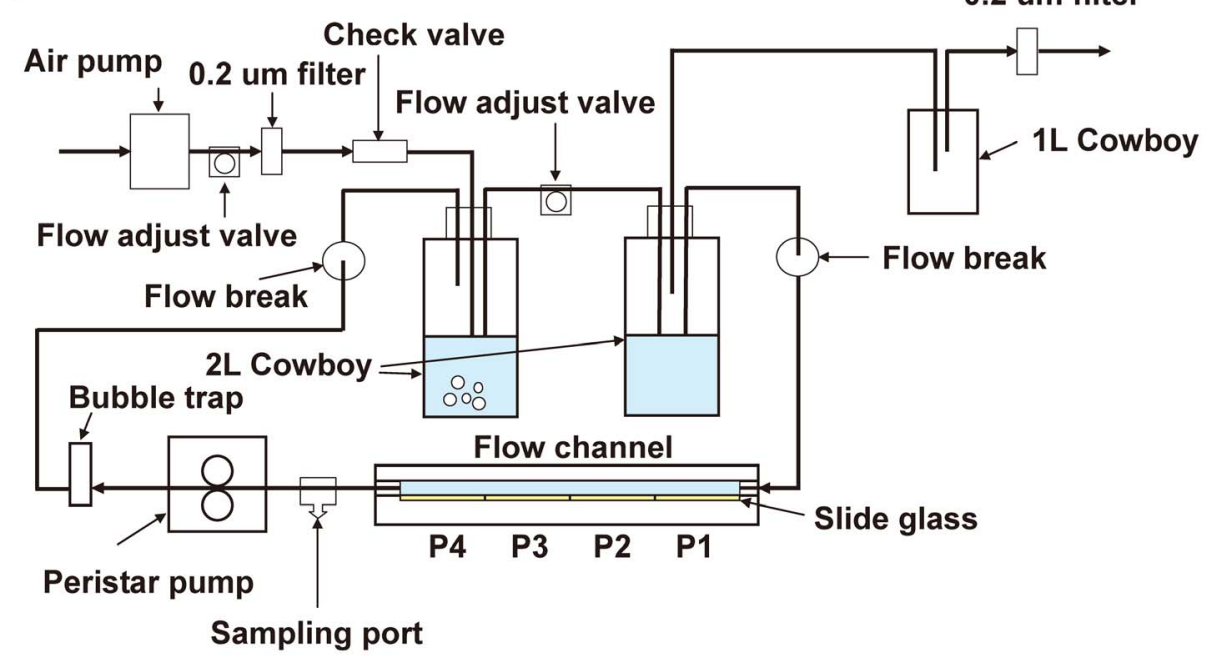

(B)

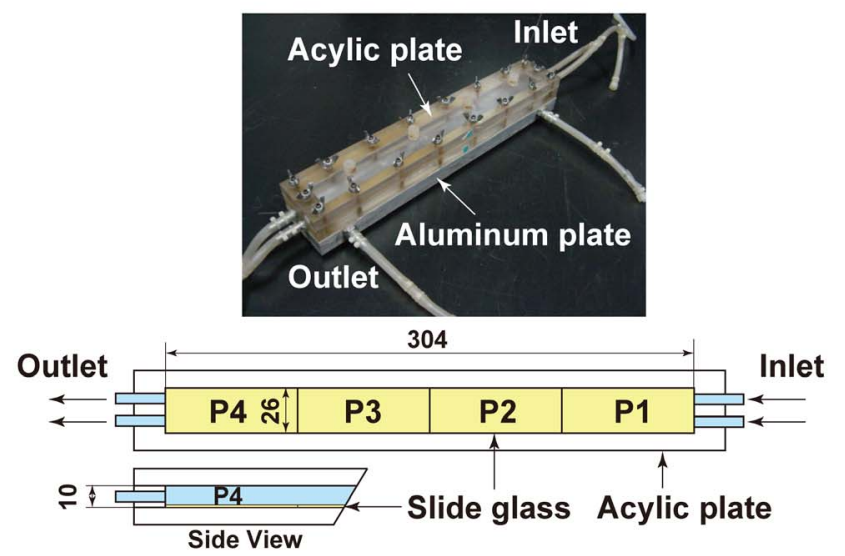

Fig.3 (A) Liquid flow chamber system (CFCS), (B) Flow channel

connected to the bottle. A check valve was used to stop backflow and protect Legionella containing medium spill out of the system by a sudden backflow surge that might occur. The air pressure inside the bottle was so devised to push the medium into the other bottle through silicon tube and the flow adjust valve. Then, the air passed through a $0.2 \mu \mathrm{m}$ membrane filter to remove Legionella and was exhausted to the atmosphere. The system was rinsed excessively with sterile water and autoclaved before use and was assembled in an incubator. The flow channel, two bottles, and other apparatus were assembled carefully to avoid contamination.

\section{Flow chamber experiments}

A c.a. $200 \mu \mathrm{l}$ aliquot of $L$. pneumophila suspensions was transferred into a centrifuge tube containing $50 \mathrm{ml}$ of fresh BCYE- $\alpha$ medium containing supplements of $1 \%$ L-cysteine and $1 \%$ ferric pyrophosphate. Prier to the biofilm experiments, BCYE- $\alpha$ containing with $L$. pneumophila was installed in the flow channel and incubated overnight at $37^{\circ} \mathrm{C}$ for the initial colonies on the glass slides to grow. Then, $300 \mathrm{~mL}$ of sterilized BCYE- $\alpha$ medium containing supplements of $1 \% \mathrm{~L}$-cysteine and $1 \%$ ferric pyrophosphate was diluted with the distilled water to make $1200 \mathrm{~mL}$ medium. The final concentration in the system was adjusted to approximately $1 \times 10^{6}$ bacteria $\mathrm{mL}^{-1}$. The medium was divided equally between the two bottles. The experiments were performed by recirculating BCYE- $\alpha$ containing with L. pneumophila in the flow channel, where biofilms accumulated onto the slides. The liquid flow chamber system was incubated between $37^{\circ} \mathrm{C}$ to $42^{\circ} \mathrm{C}$ in each independent experiment. The routine operating conditions included a flow rate of $100 \mathrm{~mL} / \mathrm{min}$. and each experiment 
was performed over a period of 8 days. Under liquid culture conditions, the pattern of biofilm development involves initial attachment to a solid surface ( 0 to 2 hours), the formation of micro-colonies on the surface (2hours to 3days), maturation of attached bacteria into a differentiated into exopolysaccharide-encased (3days to 9days) and detachment and dispersal of planktonic cells from biofilms (9days to 12days) ${ }^{(14)(19)(20)}$. The each experiment was performed over a period of 8 days after 1 day pre-incubation. We avoided the experiments after 9 days due to few cell clusters might be observed for the dispersion of attached bacteria from slide glasses. The average flow velocity in the channel is $0.64 \mathrm{~cm} / \mathrm{sec}$. At this flow velocity, the Reynolds (Re) numbers were 108 . The Re numbers for laminar flow condition was determined in order to comparison with other studies ${ }^{(21)}$. During the experiment, the samples were taken to determine the bacterial growth and find out contamination. The access port was opened and removed the portion of the medium. Care was taken that the access port was open for a minimum length of time. In this way, the survival and replication of planktonic and biofilm-associated L. pneumophila were investigated in liquid flow biofilm simulator.

Comparisons were made among biofilm formations in the liquid flow, those in static liquid and those on agar plate ${ }^{(18)}$. The incubation period is 8 days in liquid flow, 3 days in the static liquid and 1 day on the agar plate in order to adjust the incubation period to the cycle of biofilm maturation and colony growth under different conditions ${ }^{(18)}$.

\section{Confocal laser scanning microscopy (CLSM)}

At the end of the experiment, four slide glass plates were swiftly removed from the flow channel without loosening the biofilms. After they were removed, each slide was quickly but gently immersed three times in sterile water to remove unattached or loosely attached cells. The biofilms were labeled using the LIVE/DEAD BacLight ${ }^{\mathrm{TM}}$ Bacterial Viability staining kit (Invitrogen L-13152) according to the manufacturer's instructions. Briefly, biofilms were labeled with $1.67 \mu \mathrm{M}$ SYTO9 (a green fluorescent dye that can cross intact membranes) and $10 \mu \mathrm{M}$ propidium iodide (a red fluorescent dye that can only penetrate into cells that have lost membrane integrity). The biofilms were monitored through a 40x oil-immersion lens with a PASCAL LSM5 confocal laser scanning microscope (Zeiss, Germany) and examined to characterize the biofilm size, and structure under varying incubation conditions. Z-stack images were collected via confocal microscopy. Data processing and three-dimensional reconstruction were performed with the LSM Image Browser Rel. 4.2 software package (Zeiss, Germany). Images were converted to gray scale Tiff images by Photoshop CS4 ${ }^{\mathrm{TM}}$ (Adobe Corp.). Gray scale images were converted into black and white, and compared with the original image to determine the threshold for the images, and the best value was chosen to give the most accurate conversion of the gray-scale to the black/white picture. The entire area or portions of an image, size etc. were computed by Motic Images Version 2.2s Software (Motic Instruments, Inc.). The threshold value was fixed and then used for all images. Significance of differences between average values was analyzed by $t$-tests using MS Excel.

\section{Results}

To characterize the ability of $L$. pneumophila to form biofilm on glass surfaces in liquid flow, the three-dimensional structure of 8-days biofilms was analyzed using CLSM. Representative biofilm structures incubated at $37^{\circ} \mathrm{C}$ are presented in Fig.4. By day 8, biofilms of $L$. pneumophila began to form, where they formed microcolonies with a diameter of 20 to $120 \mu \mathrm{m}$ (Fig.4A). The most interesting observation was that the microcolonies showed areas of hollowing (Fig.4B). A three-dimensional reconstruction image of the hollowing microcolony (Fig.4B) is shown in Fig.4C. In order to clarify the properties of biofilms, the black/white picture, which was performed image processing by Photoshop CS4 ${ }^{\mathrm{TM}}$ and Motic Images Version 2.2s Software, is shown in Fig.4D. 


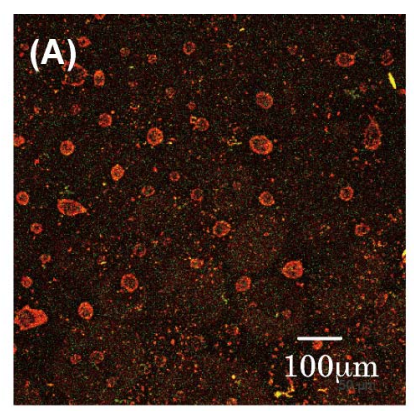

(C)

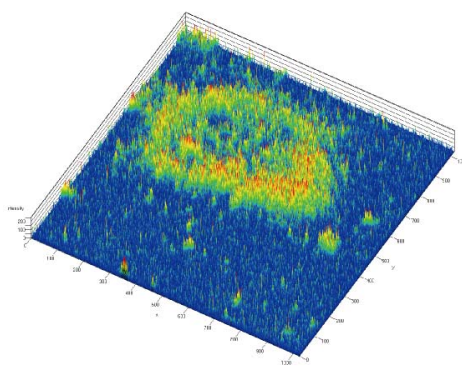

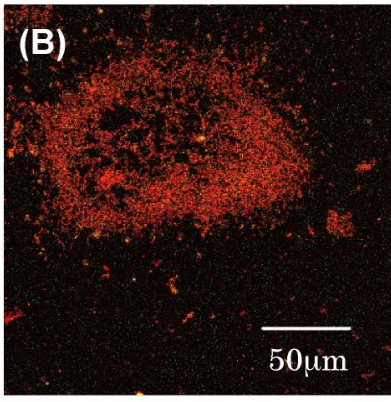

(D)

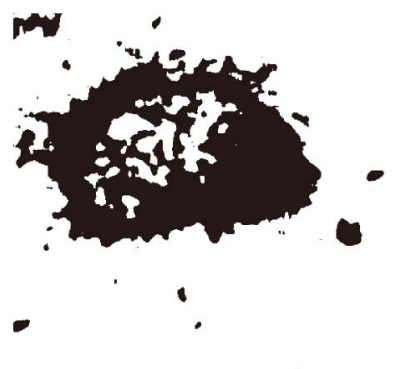

Fig.4 Biofilm formation by L. pneumophila under liquid flow with BCYE- $\alpha$ medium at $37^{\circ} \mathrm{C}$. (A) LSMS appearance of a representative biofilm section formed in a glass slide of 8-day-old L. pneumophila biofilm; (B) high magnification LSMS micrograph of (A); (C) a three-dimensional reconstruction of (B); (D) identical black/white picture of (B)

Table 1 shows the number of analyzed colonies, equivalent outer diameter $\left(D_{o d}\right)$, attached circular diameter $\left(\mathrm{D}_{\mathrm{at}}\right)$, emptiness $\left(\mathrm{E}_{\mathrm{mp}}\right)$ of the attached cell clusters on each of the four glass slides in continues-flow chamber incubated at $37^{\circ} \mathrm{C}$. The equivalent outer diameter of a non-circular colony is equal to a diameter of a circular colony that exhibits identical area. The attached circular diameter is equal to a diameter of a circular colony that attached area of bacteria exhibits identical. The emptiness (hollowness) of colony is defined as the ratio of biofilm non-attached areas to attached areas,

$$
E_{m p}=\frac{D_{o d}^{2}-D_{a t}^{2}}{D_{o d}^{2}}
$$

The glass slides are identified as P1 to P4 in the direction of upstream to down-stream in the continues-flow chamber. In Fig.5, the bars indicate the averages for the analyzed colonies, and the error bars indicate standard deviations. On P1 near the inlet of the flow chamber, no biofilm colonies were observed. L. pneumophila formed microcolonies with an equivalent outer diameter of $87 \pm 32 \mu \mathrm{m}$ on P2, $138 \pm 81 \mu \mathrm{m}$ on P3 and $35 \pm 14 \mu \mathrm{m}$ on P4. The attached circular diameter was $62 \pm 23 \mu \mathrm{m}$ on P2, $81 \pm 25 \mu \mathrm{m}$ on P3 and $27 \pm 9 \mu \mathrm{m}$ on P4. The emptiness of colony was $43 \pm 4 \%$ on P2, $43 \pm 18 \%$ on P3 and $35 \pm 16 \%$ on P4. In statistical significance testing, the $P$ value is the probability of obtaining a test statistic at least as extreme as the one that was actually observed, with a value ranging from zero to one. The smaller the $P$ value is, the more significant the test result is statistically. The statistically significant differences were observed between P2 and P4 $(P<0.01)$, between P3 and P4 $(P<0.01)$ in an equivalent outer diameter and attached circular diameter. However, there was no significant differences were observed for emptiness $(P>0.1)$.

Figure 6 shows CLMS two-dimensional appearance of a representative biofilm section formed in a glass slide of 8-day-old L. pneumophila biofilm under the liquid flow in BCYE- $\alpha$ medium (A) at $37^{\circ} \mathrm{C}$, (B) $40^{\circ} \mathrm{C}$ and (C) $42^{\circ} \mathrm{C}$. Table 2 shows the properties of $L$. pneumophila biofilm microcolonies at 37,40 , and $42^{\circ} \mathrm{C}$ on glass slides surfaces inoculated in liquid flow condition. Data from three independent experiments were averaged over four 
glass slides. Figure 7 shows Effects of incubation temperature on L. pneumophila biofilm properties. The symbols indicate the averages for the analyzed colonies, and the error bars indicate standard deviations. The equivalent outer diameter was $27 \pm 15 \mu \mathrm{m}$ at $37^{\circ} \mathrm{C}, 189 \pm$ $77 \mu \mathrm{m}$ at $40^{\circ} \mathrm{C}$ and $359 \pm 85 \mu \mathrm{m}$ at $42^{\circ} \mathrm{C}$, respectively. The attached circular diameter was $39 \pm 56 \mu \mathrm{m}$ at $37^{\circ} \mathrm{C}, 99 \pm 37 \mu \mathrm{m}$ at $40^{\circ} \mathrm{C}$ and $154 \pm 21 \mu \mathrm{m}$ at $42^{\circ} \mathrm{C}$, respectively. The emptiness of colony was $37 \pm 15 \%$ at $37^{\circ} \mathrm{C}, 52 \pm 12 \%$ at $40^{\circ} \mathrm{C}$ and $74 \pm 8 \%$ at $42^{\circ} \mathrm{C}$, respectively. The equivalent outer diameter, attached circular diameter and emptiness increased with the rise of the temperature.

Table 1 Properties of L. pneumophila biofilm microcolonies incubated at $37^{\circ} \mathrm{C}$

\begin{tabular}{cccccccc}
\hline \multirow{2}{*}{ Position } & \multirow{2}{*}{$\begin{array}{c}\text { Number of } \\
\text { colonies }\end{array}$} & \multicolumn{2}{c}{ Outer dia. $(\mu \mathrm{m})$} & Attached dia. $(\mu \mathrm{m})$ & \multicolumn{2}{c}{ Emptiness $(\%)$} \\
\cline { 2 - 8 } & Average & S.D. & Average & S.D. & Average & S.D. \\
\hline P1 & 0 & 0 & 0 & 0 & 0 & 0 & 0 \\
\hline P2 & 6 & 87 & 32 & 62 & 23 & 43 & 4 \\
\hline P3 & 18 & 138 & 81 & 81 & 25 & 43 & 18 \\
\hline P4 & 79 & 35 & 14 & 27 & 9 & 35 & 16 \\
\hline
\end{tabular}

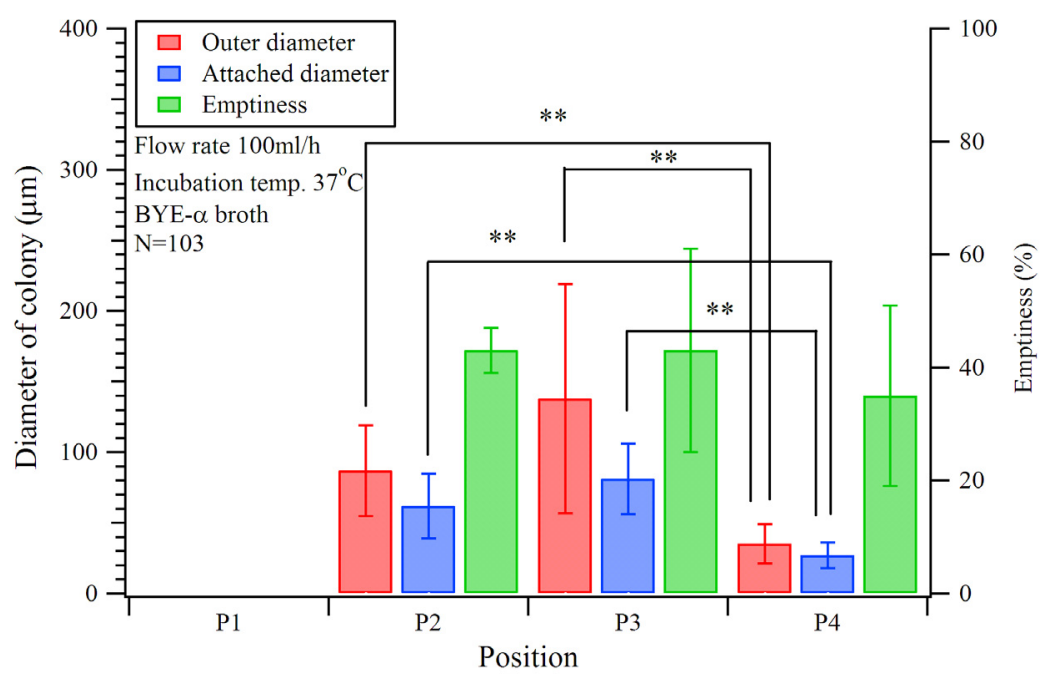

Fig.5 Properties of 8-day-old L. pneumophila biofilm grown on four slides in flow chamber at $37^{\circ} \mathrm{C}$. Symbols of $P$ value for t-testing are $*: P<0.05$ and $* *: P<0.01$.
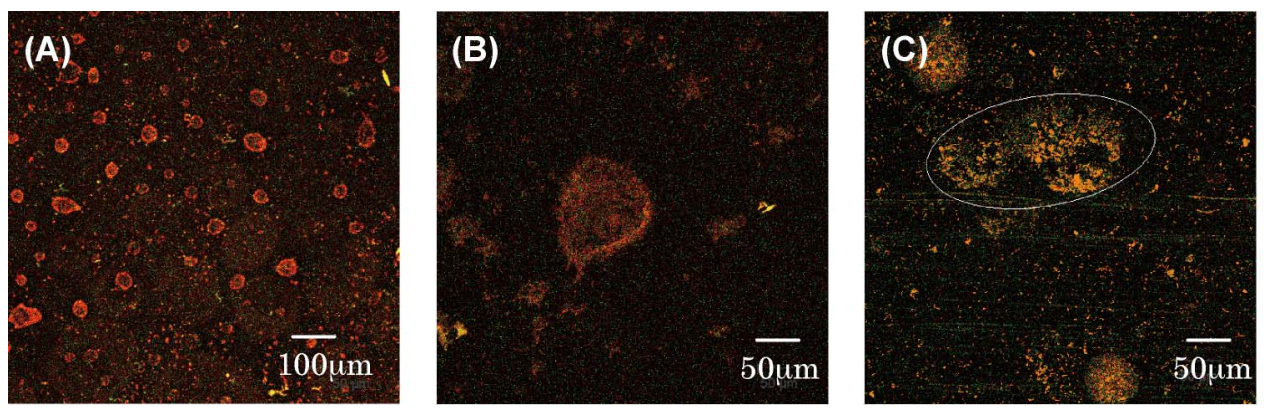

Fig.6 CLMS appearance of a representative biofilm section formed on a glass slide of 8-day-old L. pneumophila biofilm. Effects of incubation temperature on $L$. pneumophila biofilm properties under liquid flow with BCYE- $\alpha$ medium (A) $37^{\circ} \mathrm{C}$; (B) $40^{\circ} \mathrm{C}$; (C) $42^{\circ} \mathrm{C}$. 
Table 2 Properties of L. pneumophila biofilm microcolonies incubated at 37,40 and $42^{\circ} \mathrm{C}$

\begin{tabular}{cccccccr}
\hline \multirow{2}{*}{$\begin{array}{c}\text { Incubation } \\
\text { temp. }\left({ }^{\circ} \mathrm{C}\right)\end{array}$} & $\begin{array}{c}\text { Number of } \\
\text { colonies }\end{array}$ & \multicolumn{2}{c}{ Outer dia. $(\mu \mathrm{m})$} & \multicolumn{2}{c}{ Attached dia. $(\mu \mathrm{m})$} & \multicolumn{2}{c}{ Emptiness $(\%)$} \\
\cline { 2 - 8 } & Average & S.D. & Average & S.D. & Average & S.D. \\
\hline 37 & 103 & 39 & 56 & 27 & 15 & 37 & 15 \\
\hline 40 & 58 & 189 & 77 & 99 & 37 & 52 & 12 \\
\hline 42 & 15 & 359 & 85 & 154 & 21 & 74 & 8 \\
\hline
\end{tabular}

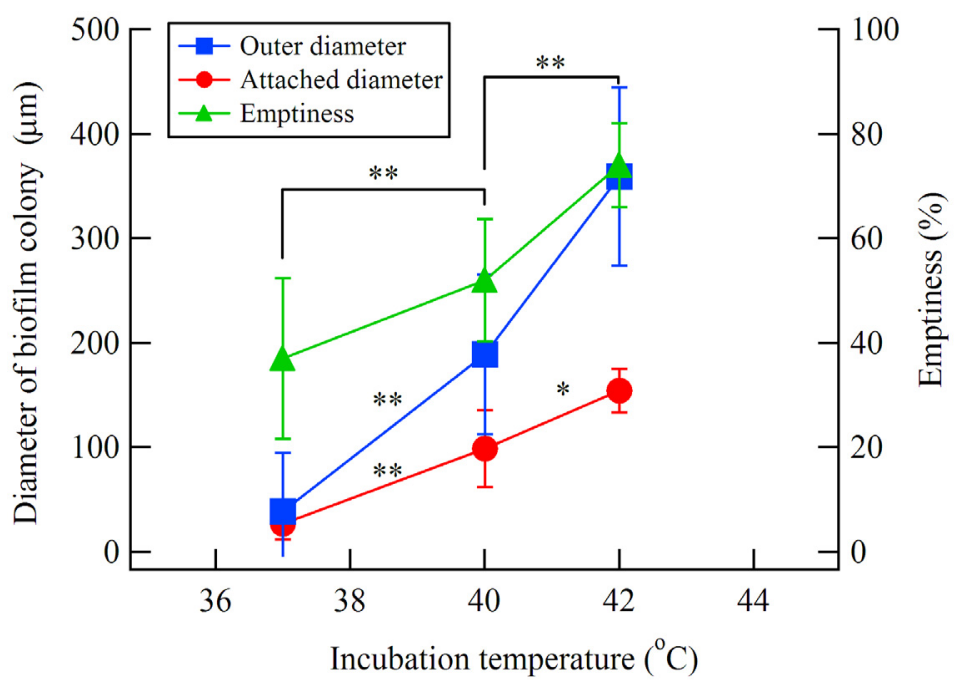

Fig.7 Effects of incubation temperature on L. pneumophila biofilm properties.

Symbols of $P$ value for t-testing are $*: P<0.05$ and $* *: P<0.01$.

Fig.8A shows the light microscopy photography of a biofilm of L. pneumophila in liquid flow of BCYE- $\alpha$ medium at $37^{\circ} \mathrm{C}$. The biofilm composed of microbial assemblages of L. pneumophila was observed. Fig.8B shows magnified light microscopic photography of Fig.8A. The biofilm exhibited a typical hollow microcolony which was composed of short rod bacteria. Fig.8C shows the photograph of thick L. pneumophila biofilm developed on the glass wall, on the air-liquid at $40^{\circ} \mathrm{C}^{(16)}$. Fig.8D is light microscopic photography of Fig.8C. The biofilm exhibited a typical filamentous morphology that did not differ much whenever the bacteria were located in the biofilm. Fig.8E shows the streak of $L$. pneumophila developed on BCYE- $\alpha$ agar plate at $37^{\circ} \mathrm{C}$. The light microscopic exhibited a typical filamentous morphology in Fig.8F. Table 3 is a comparison of L. pneumophila bacteria length of a biofilm in liquid flow with BCYE- $\alpha$ medium, on the glass wall in static liquid and on BCYE- $\alpha$ agar plate. The average length was $4.4 \pm 1.7 \mu \mathrm{m}$ at $37^{\circ} \mathrm{C}, 2.9 \pm 1.2$ $\mu \mathrm{m}$ at $40^{\circ} \mathrm{C}, 3.5 \pm 2.0 \mu \mathrm{m}$ at $42^{\circ} \mathrm{C}$ in the liquid flow, respectively. The average length was $28 \pm 15 \mu \mathrm{m}$ at $37^{\circ} \mathrm{C}, 50 \pm 20 \mu \mathrm{m}$ at $40^{\circ} \mathrm{C}$ and $80 \pm 26 \mu \mathrm{m}$ at $42^{\circ} \mathrm{C}$ in static liquid, respectively. The average length on agar plate was $58 \pm 36 \mu \mathrm{m}$ at $37^{\circ} \mathrm{C}, 98 \pm 44 \mu \mathrm{m}$ at $40^{\circ} \mathrm{C}$ and $125 \pm 68 \mu \mathrm{m}$ at $42^{\circ} \mathrm{C}$, respectively. Figure 9 shows the length of L. pneumophila bacteria in static liquid and on BCYE- $\alpha$ agar plate increased with the temperature, respectively. However, the length of L. pneumophila bacteria in liquid flow did not differ with the temperature.

\section{Discussion}

Microcolonies of L. pneumophila biofilms on glass surface in liquid flow channel were observed by confocal laser scanning microscopy (Fig.4A). The average number of legionella bacteria per single colony includes $4.9 \times 10^{4}$ in P2, $1.3 \times 10^{5}$ in P3 and $1.2 \times 10^{4}$ 

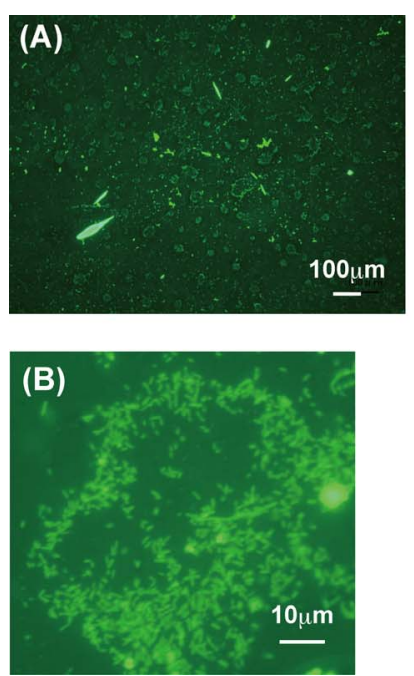
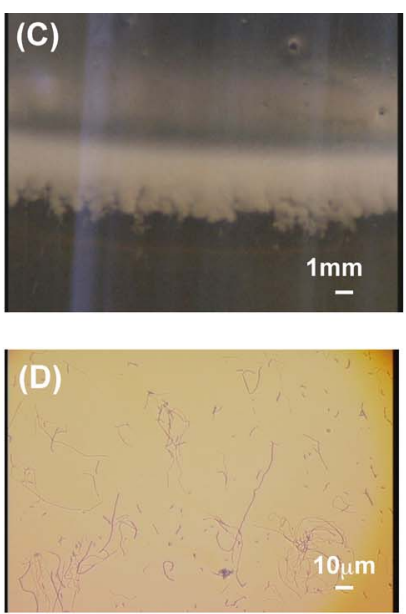

Fig.8 (A) CLMS biofilm image of L. pneumophila in liquid flow with BCYE- $\alpha$ medium at $37^{\circ} \mathrm{C}$; (B) light microscopic photography of (A); (C) photograph of thick L. pneumophila biofilm developed on the glass wall, on the air-liquid at $40^{\circ} \mathrm{C}$ in static liquid ${ }^{(18)}$; (D) light microscopic photography of (C); (E) L. pneumophila streaked on BCYE- $\alpha$ agar plate at $37^{\circ} \mathrm{C}$; (F) light microscopic photography of (E).

Table 3 Properties of L. pneumophila biofilm

\begin{tabular}{ccccccc}
\hline \multirow{2}{*}{$\begin{array}{c}\text { Incubation } \\
\text { temp. }\left({ }^{\circ} \mathrm{C}\right)\end{array}$} & \multicolumn{2}{c}{ Liquid flow } & \multicolumn{2}{c}{ Static liquid } & \multicolumn{2}{c}{ Agar plate } \\
\cline { 2 - 7 } & Average & S.D. & Average & S.D. & Average & S.D. \\
\hline 37 & 4.4 & 1.7 & 28 & 15 & 58 & 36 \\
\hline 40 & 2.9 & 1.2 & 50 & 20 & 98 & 44 \\
\hline 42 & 3.5 & 2.0 & 80 & 26 & 125 & 68 \\
\hline
\end{tabular}

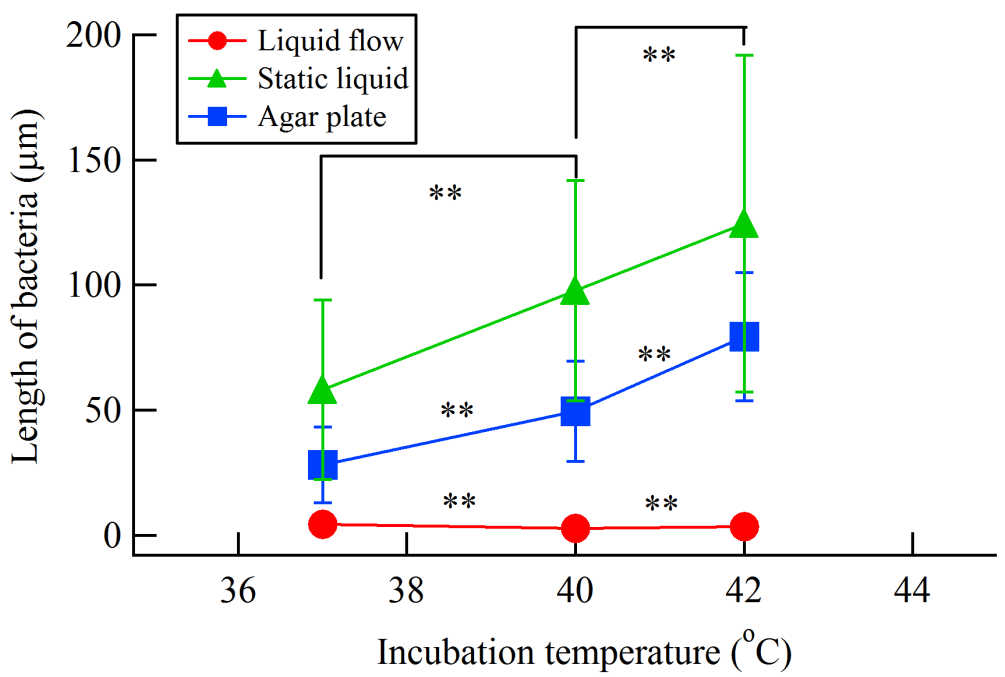

Fig.9 Comparisons were made among bacterial length in the liquid flow and those in the static condition and those on agar plate. Symbols of $P$ value for t-testing are $*: P<0.05$ and $* *: P<0.01$. 
in $\mathrm{P} 4$ at $37^{\circ} \mathrm{C}$. The number of $L$. pneumophila in a single colony, each of which measured $0.3-0.9 \mu \mathrm{m}$ in diameter, was calculated using the average bacteria length as shown in Table 3 , the colony height (c.a. $20 \mu \mathrm{m}$, measured by CLMS) and the attached circular diameter.

The current Japanese regulatory safety level for Legionella in bathwater, which is set below the detection limit of culture techniques $(10 \mathrm{cfu} / 100 \mathrm{ml})$, should be appropriate to prevent bathwater-associated legionellosis. If more than a single colony which has $1 \times 10^{5}$ Legionella bacteria is detached from glass wall and dispersed into a bath tub containing 1000 liter of water, the number of legionella easily exceeds the required safety regulations of $10 \mathrm{cfu} / 100 \mathrm{ml}$. Also, biofilm detachment and the interaction of Legionella with acanthamoebae enhance the multiplication of Legionella that significantly increased the risk of legionellosis ${ }^{(22)}$.

The emergence of L. pneumophila between 5.7 and $63^{\circ} \mathrm{C}$ in natural environments has demonstrated the ability of the pathogen to survive over a wide temperature range ${ }^{(7)}$. Optimum growth of L. pneumophila in water occurred at $37^{\circ} \mathrm{C}$, and growth was prevented at $42^{\circ} \mathrm{C}^{(23)(24)}$.

In our study, we revealed that the temperature between $37^{\circ} \mathrm{C}$ and $42^{\circ} \mathrm{C}$ influence on biofilm formation and bacteria length on the glass wall in liquid flow chamber, on the glass wall in static liquid and on BCYE- $\alpha$ agar plate. We found that the equivalent outer diameter, attached circular diameter and emptiness increased with the temperature (Fig.6, Fig.7, Table 2). The L. pneumophila cell growth was inhibited over $42^{\circ} \mathrm{C}$, therefore we considered that the growth of biofilms might also be inhibited.

Other bacteria, Serratia marcescens, for example, go through a similar reproduction process of attachment, aggregation, microcolony development, hollow colony formation, and dispersal. However, their reproduction occurs at lower temperature and in a shorter period of time than Legionella. Hollow colonies of Serratia marcescens were observed in flow cell biofilms after 3 to 4 days at $30^{\circ} \mathrm{C}^{(20)(22)}$.

In our study, hollow colonies were observed at $37^{\circ} \mathrm{C}$ (Fig.6A), $40^{\circ} \mathrm{C}$ (Fig.6B) in 8-days. The biofilms incubated at $42^{\circ} \mathrm{C}$ (Fig.6C) exhibit dispersal stages on surfaces and release cells into the environment to colonize new sites. Thus, we consider that higher temperature may contribute to biofilm maturation of L. pneumophila. The length of L. pneumophila bacteria in static liquid and on BCYE- $\alpha$ agar plate increased with the rise of temperature, the bacteria length did not change as the temperature changed in liquid flow (Fig.8, Fig.9, Table 3). In the static liquid (Fig.8B) and on BCYE- $\alpha$ agar plate (Fig.8C), a rise of temperature caused L. pneumophila cell elongation, i.e. filamentous cells. On the contrary, in liquid flow, cells kept rod shaped in spite of the changes of incubation temperature (Fig.9).

Ott et al. revealed that flagellation of Legionellae was also temperature regulated between $37{ }^{\circ} \mathrm{C}$ to $41{ }^{\circ} \mathrm{C}^{(25)}$. When the growth temperature of virulent and avirulent of strain L. pneumophila was shifted from $30^{\circ} \mathrm{C}$ to either 37 or $41{ }^{\circ} \mathrm{C}$, a decrease in the percentage of flagellated bacteria within the population was observed. Another study showed that $\mathrm{ClpP}$ was required for optimal growth of L. pneumophila at high temperatures and under several other stress conditions ${ }^{(26)}$. They observed that cells devoid of ClpP exhibited cell elongation, incomplete cell division and compromised colony formation.

Piao et al. examined for biofilm formation of fifty strains representing 38 species of the genus Legionella were on glass, polystyrene, and polypropylene surfaces in static cultures at $25^{\circ} \mathrm{C}, 37^{\circ} \mathrm{C}$, and $42^{\circ} \mathrm{C}^{(27)}$. They revealed that biofilms formed at $37^{\circ} \mathrm{C}$ or $42^{\circ} \mathrm{C}$ were mycelial mat like and were composed of filamentous cells, while at $25^{\circ} \mathrm{C}$, cells were rod shaped. Planktonic cells outside of biofilms or in shaken liquid cultures were rod shaped. However, they also showed that filamentous cells were able to rapidly give rise to a large number of short rods in a fresh liquid culture at $37^{\circ} \mathrm{C}$. The nutrient limitation, such as biofilm formed at air-liquid interface (Fig.8B) or cell pile up on top of other colonies (Fig. $8 \mathrm{C}$ ), may regulate optimal growth genes $\mathrm{ClpP}$ and exhibites incomplete cell division. 
Considering these studies, we deduce that ClpP may be induced in nutrient rich flow conditions.

For concerning P. aeruginosa PAO1 biofilms, Purevdorj B et al. ${ }^{(21)}$ and Stoodley et al. ${ }^{(28)}$ reported that, under conditions of low-shear laminar flow, the biofilm consisted of a monolayer of cells with mound-shaped circular microcolonies but under high-shear, turbulent flow conditions, the biofilm formed filamentous streamers. Their biofilm simulator has two glass tube flow cells, $20 \mathrm{~cm}$ long and $3 \mathrm{~mm}$ in width and height. The flow velocity was maintained at $3.3 \mathrm{~cm} / \mathrm{s}(\mathrm{Re}=100)$ in one flow cell for laminar flow and at 1.0 $\mathrm{m} / \mathrm{s}(\mathrm{Re}=3000)$ in the other flow cell for turbulent flow at $37^{\circ} \mathrm{C}$.

In our experiments, L. pneumophila biofilms, the average flow velocity in the channel is $0.64 \mathrm{~cm} / \mathrm{sec}$ and the Reynolds numbers are 108 for laminar flow condition. The similar mound-shaped circular microcolonies of L. pneumophila biofilms were observed at $37^{\circ} \mathrm{C}$. For fast fluid flow, the hydrodynamic analysis predicted that area blocked by the adhering organism at a substratum surface modify the colony shape form circular to oval-shaped ${ }^{(29) \text {. }}$ Futures studies for the effect of share stress on biofilm formation are a required.

In summary, we have initiated studies on the formation of L. pneumophila biofilm, facilitated by the recent development of a liquid flow biofilm simulator. Although this model does not reflect the complexity found in natural environmental biofilms, monospecies biofilms were the first step towards understanding the sessile lifestyle for $L$. pneumophila. Our results on biofilm formation of $L$. pneumophila provide the basis for a better understanding of the sessile mode of life of $L$. pneumophila. Gaining knowledge about mechanisms regulating biofilm formation can potentially lead to better strategies for the prevention and treatment of biofilm-associated infections. It will be challenging to explore the complex interactions between temperature and biofilm formation.

\section{Acknowledgements}

This research was sponsored in part by a grant-in-aid (No. 15500337 and No. 17500324) for Science Research from the Ministry of Education, Science, and Culture of Japan. The authors would like to thank to Ms. Kimiko Wakamatsu for assistance with manuscript preparation.

\section{References}

(1) Fields, B.S., The social life of Legionellae. In: Legionella, Marre, R. Eds., (2002), pp.135-142, American Society of Microbiology press Washington DC.

(2) Rogers, F.G, Chapter 49. Legionella, In Collier, L., Balows, A. and Sussman, M., Eds., Topley's and Wilson's Microbiology and Microbial infections 9th Ed., (1998), pp.1147-1165, Oxford University Press.

(3) Annual Surveillance Data (Notifiable Diseases) Category IV, Infectious Disease Surveillance Center. (online), available from<http://idsc.nih.go.jp/idwr/ydata/report-Ea.html). >, (accessed 2011-1-20).

(4) Surveillance of Legionella in public facilities in the first half of 2010, Public Health Weekly Report Vol.3, No.35 (2010), Korea Centers for Disease Control and Prevention.

(5) Atlas, R.M., Legionella: from environmental habitats to disease pathology, detection and control. Environ. Microbiol., Vol.1 (1999), pp.283-293.

(6) Ciesielski, C.A., Blaser, M.J., and Wang, W.L.: Role of stagnation and obstruction of water flow in isolation of Legionella pneumophila from hospital plumbing, Appl. Environ. Microbiol., Vol.48 (1984), pp.984-987.

(7) Fliermans, C.B., Cherry, W.B., Orrison, L.H., Smith, S.J., Tison, D.L., and Pope, D.H., Ecological distribution of Legionella pneumophila. Appl. Environ. Microbiol., Vol.41 (1981), pp.9-16.

(8) Nguyen TM, Ilef D, Jarraud S, Rouil L, Campese C, Che D, Haeghebaert S, Ganiayre F, Marcel F, Etienne J, Desenclos JC., A community-wide outbreak of legionnaires disease 
linked to industrial cooling towers--how far can contaminated aerosols spread?, J Infect Dis. Vol.193, No.1 (2006), pp.102-111

(9) Brieland JK, Fantone JC, Remick DG, LeGendre M, McClain M, Engleberg NC., The role of Legionella pneumophila-infected Hartmannella vermiformis as an infectious particle in a murine model of Legionnaire's disease., Infect Immun. Vol.65, No.12 (1997), pp.5330-5333.

(10) Isozumi, R., Ito, Y., Ito, I., Osawa, M., Hirai, T., Takakura, S., Iinuma, Y., Ichiyama, S., Tateda, K., Yamaguchi, K., and Mishima, M., An outbreak of Legionella pneumonia originating from a cooling tower. Scand. J. Infect. Dis., Vol.37 (2005), pp.709-711.

(11) Feazel LM, Baumgartner LK, Peterson KL, Frank DN, Harris JK, Pace NR., Opportunistic pathogens enriched in showerhead biofilms., Proc Natl Acad Sci U S A. Vol.106, No.38 (2009), pp.16393-16399.

(12) Kuiper, M. W., R. M. Valster, B. A. Wullings, H. Boonstra, H. Smidt, and D. van der Kooij, Quantitative detection of the free-living amoeba Hartmannella vermiformis in surface water by using real-time PCR. Appl. Environ. Microbiol. Vol.72 (2006), pp.5750-5756.

(13) Farhat $\mathrm{M}$ et al., Development of a pilot-scale 1 for Legionella elimination in biofilm in hot water network: heat shock treatment evaluation, J Appl Microbiol. Vol.108, Issue 3 (2010), pp. 1073-1082.

(14) JW Costerton, PS Stewart and EP Greenberg, Bacterial biofilms: a common cause of persistent infections, Science 284 (1999), pp.1318-1322.

(15) I.W. Sutherland, The biofilm matrix - an immobilized but dynamic microbial environment. Trends Microbiol Vol.9 (2001), pp. 222-227.

(16) Fisher-Hoch, S.P., Bartlett, C.L., Tobin, J.O., Gillett, M.B., Nelson, A.M., Pritchard, J.E., Smith, M.G., Swann, R.A., Talbot, J.M., and Thomas, J.A., Investigation and control of an outbreaks of legionnaires' disease in a district general hospital. Lancet Apr., Vol.25 (1981), pp.932-936.

(17) Stout, J.E., Best, M.G., and Yu, V.L., Susceptibility of members of the family Legionellaceae to thermal stress: Implication for heat eradication methods in water distribution systems. Appl. Environ. Microbiol., Vol.52 (1986), pp.396-399.

(18) Konishi T, Yamashiro T, Koide M, Nishizono A., Influence of temperature on growth of Legionella pneumophila biofilm determined by precise temperature gradient incubator. $\mathrm{J}$ Biosci Bioeng. Vol.101, No.6 (2006), pp.478-84.

(19) Sauer K, Camper AK, Ehrlich GD, Costerton JW, Davies DG., Pseudomonas aeruginosa displays multiple phenotypes during development as a biofilm., J Bacteriol. Vol.184, No.4(2002), pp.1140-1154.

(20) Koh KS, Lam KW, Alhede M, Queck SY, Labbate M, Kjelleberg S, Rice SA., Phenotypic diversification and adaptation of Serratia marcescens MG1 biofilm-derived morphotypes. J Bacteriol. Vol.189, No.1 (2007), pp.119-130.

(21) Purevdorj B, Costerton JW, Stoodley P., Influence of hydrodynamics and cell signaling on the structure and behavior of Pseudomonas aeruginosa biofilms., Appl Environ Microbiol. Vol.68, No.9(2002), pp.4457-4464.

(22) Ohno A, Kato N, Sakamoto R, Kimura S, Yamaguchi K., Temperature-dependent parasitic relationship between Legionella pneumophila and a free-living amoeba (Acanthamoeba castellanii), Appl Environ Microbiol. Vol.74, No.14 (2008), pp.4585-4588.

(23) Wadowsky RM, Yee RB., Effect of non-Legionellaceae bacteria on the multiplication of Legionella pneumophila in potable water., Appl Environ Microbiol. Vol.49, No.1 (1985), pp.1206-1210.

(24) Wadowsky RM, Butler LJ, Cook MK, Verma SM, Paul MA, Fields BS, Keleti G, Sykora JL, Yee RB., Growth-supporting activity for Legionella pneumophila in tap water cultures and implication of hartmannellid amoebae as growth factors., Appl Environ Microbiol. Vol.54, No.11 (1988), pp.2677-2682.

(25) Ott M, Messner P, Heesemann J, Marre R, Hacker J., Temperature-dependent expression of 
flagella in Legionella, J Gen Microbiol. Vol.137, No.8 (1991), pp.1955-1961.

(26) Li XH, Zeng YL, Gao Y, Zheng XC, Zhang QF, Zhou SN, Lu YJ., The ClpP protease homologue is required for the transmission traits and cell division of the pathogen Legionella pneumophila., BMC Microbiol. Vol.10, No.54 (2010), pp.1-15.

(27) Piao Z, Sze CC, Barysheva O, Iida K, Yoshida S., Temperature-regulated formation of mycelial mat-like biofilms by Legionella pneumophila., Appl Environ Microbiol. Vol.72, No.2 (2006), pp.1613-1622.

(28) Stoodley, P., F. Jorgensen, P. Williams, and H. M. Lappin-Scott. 1999. The role of hydrodynamics and ahl signaling molecules as determinants of structure of Pseudomonas aeruginosa biofilms, p. 323-330. In R. Bayston et al. (ed.), Biofilms: the good, the bad, and the ugly. BioLine Press, Cardiff, United Kingdom.

(29) Busscher HJ, van der Mei HC., Microbial adhesion in flow displacement systems., Clin Microbiol Rev., Vol.9, No.1(2006), pp.127-141. Review. 